\title{
Reduction of the Patient Hygiene Performance Index Based on an Oral Hygiene Program Using Oral Camera
}

\author{
Sun-ju Kim \\ Dept. of dental hygiene, Cheongju University, Korea \\ sjkim@cju.ac.kr
}

\begin{abstract}
Considering the increased incidence of oral diseases and continuous increase in dental costs, and the escalating implementation of ICT and U-healthcare, we here investigated the effect of a remote oral hygiene management program for reducing dental plaque, based on communication between a hospital and patients using information and communication technology. The plaque index of the participants in this study decreased markedly by the end of the program, indicating that the program improved the oral hygiene status of participants by improving their oral hygiene skills, subsequently leading to effective removal of dental plaque. This study illustrates a new oral hygiene management model that may suit the changing dental field by verifying the effectiveness of an oral hygiene program.
\end{abstract}

Keywords: Oral health education, Oral camera, PHP index, Dental plaque

\section{Introduction}

Information \& communication technology allows individuals to manage their own health without time and spatial restrictions and is increasingly being applied in the medical field [1][2][3][4][5]. Implementation of comprehensive oral care education using ICT, which overcomes time and spatial limitations, and does not require patients to visit a hospital or dental office, may be highly effective to resolve these issues [6][7]. Considering the converging trend of ICT and healthcare, a study that investigates the effectiveness of an oral health management program using ICT may provide significant insights in the field of dental medicine in Korea [8]. Dental caries, a serious chronic oral disease, and periodontal diseases are the major cause of dental plaque, which are aggregates of bacteria in the oral cavity [9]. Dental plaque management is the most basic step of oral disease prevention. Patients need to be educated on how to manage dental plaque to help them develop the basic abilities and skills needed to manage their oral health for their lifetime. In the dental field, there has recently been a shift from a treatment-focused approach, which is taken after the onset of an oral disease, to a prevention-focused approach [8]. Thus, the importance of personalized, oneon-one, repeated education has been emphasized as a method for the efficient management of dental plaque [9][10].

Thus, we here suggested a new oral health management model, by assessing the effect of a patient-hospital communication-based oral hygiene management program on dental plaque removal.

Article history:

Received (October 20, 2019), Review Result (December 2, 2019), Accepted (January 11, 2020) 


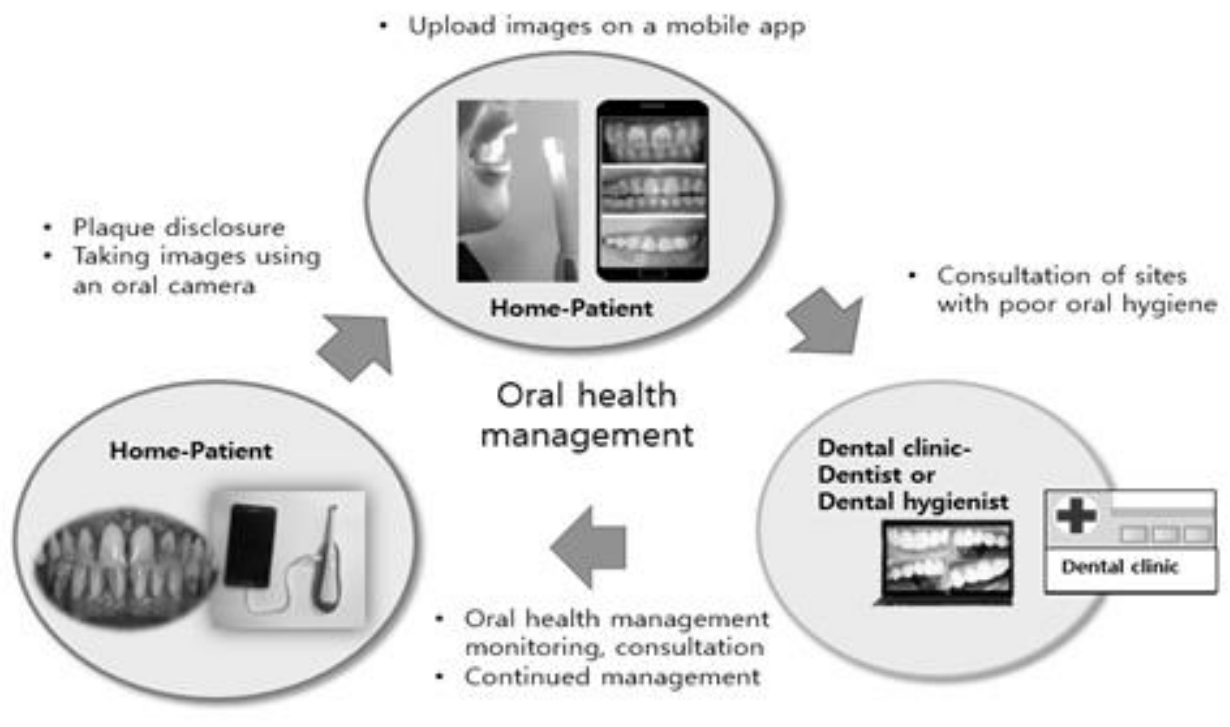

Figure 1. Oral health management service model using oral camera and smartphone

\section{Subjects and methods}

\subsection{Subjects}

This study was conducted between January 2018, and March 2018 . Although 25 patients initially participated in this study, five patients with poor attendance were excluded, and the remaining 20 participants were finally included in this pilot study.

\subsection{Subjects}

All participants were provided with an easily manipulatable oral camera (OSHIDE, Japan), a dental plaque disclosing agent, and oral hygiene care products, and received preliminary education. The participants were instructed to brush their teeth and manage their oral hygiene before applying a disclosing agent and taking images of dental surfaces using an oral camera.

\subsubsection{Preliminary education before program implementation}

Each participant visited the hospital prior to the start of the program for measurement of their patient hygiene performance (PHP) index after an oral examination. The participants were taught how to stain dental surfaces with a disclosing solution to be able to visualize dental plaque. In addition, the participants were taught how to use an oral camera, and how to upload images using the smartphone application [Table 1].

Table 1 . Preliminary educationalinformation

\begin{tabular}{|c|c|}
\hline Titles & Major contents \\
\hline $\begin{array}{c}\text { Plaque disclosure and } \\
\text { basic oral hygiene } \\
\text { education }\end{array}$ & - Lesson on identifying target teeth and dental surfaces for plaque disclosure \\
- Lesson on how to brush teeth (rotation technique) \\
- Lesson on how to use auxiliary oral health care products
\end{tabular}




\begin{tabular}{|c|c|}
\hline $\begin{array}{c}\text { Lesson on how to use } \\
\text { an oral camera }\end{array}$ & $\begin{array}{c}\text { - How to use an oral camera on a dental surface stained } \\
\text { - How to save and manage obtained images }\end{array}$ \\
\hline Use of smartphones & - Lesson on how to upload images on the hospital's mobile application \\
\hline
\end{tabular}

\subsubsection{PHP index measurement and taking images using an oral camera}

To visualize dental plaque for PHP index measurement, a plaque disclosing solution was applied to the target dental surfaces using a cotton pellet, and images of the dental surfaces were obtained using an oral camera. Participants were taught to be careful not to let the lens of the camera touch the dental surface directly while attempting to obtain a clear image of the surface. They were instructed to upload an image on the hospital's mobile application once every day after they had brushed their teeth after a meal, regardless of the time of day. A single dental hygienist at the hospital checked the uploaded image and measured the PHP index [Figure 2].

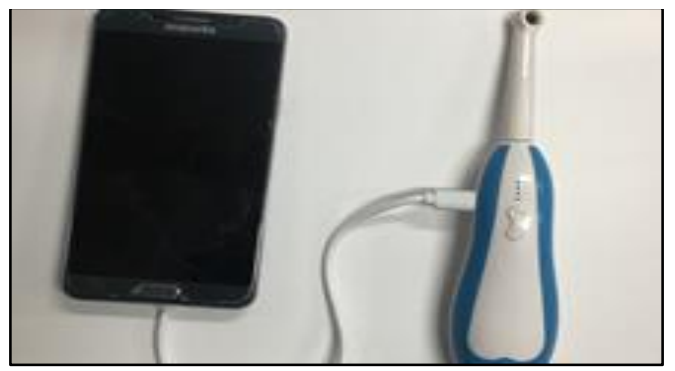

(a) Oral camera and smartphone

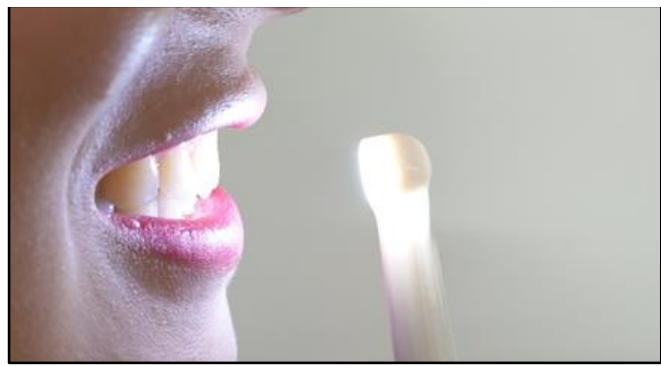

(b) Taking an image of the dental surface

Figure 2. Taking an image using an oral camera and smartphone

\subsubsection{Consultation and education regarding the PHP index measurement results}

To remove dental plaque from all teeth, it is necessary to employ an appropriate toothbrushing method, accounting for the different properties of each dental surface. An experienced clinical dental hygienist was in charge of providing education and management of patients in this study. The participants were first taught the basic toothbrushing method and were then taught how to brush teeth in different compartments of the oral cavity sequentially before starting the program. The participants then submitted a daily photographic image of their teeth after staining for plaque; this was evaluated by the dental hygienist on a daily basis.

After the PHP index was measured based on the uploaded images, the participants were educated one-on-one lessons on oral hygiene methods from dental hygienists. The participants' toothbrushing technique for areas with high rates of plaque build-up was corrected, and the participants were re-taught how to use an interdental brush and dental floss. In addition, the details of the education contents were documented and sent to the patients through social media platforms and email. The program was run for 2 weeks. A total of 10 sessions were held, five sessions per week, from Monday to Friday [Table 2].

\subsection{Statistical analysis}

All collected data were analyzed using SPSS software (SPSS Inc., Chicago, IL, USA). The participants' general characteristics were expressed as percentages, and a paired t-test was used to analyze changes in the PHP index before and after the program. The level of statistical significance was set at 0.05 . 
Table 2. Program contents

\begin{tabular}{|c|c|c|c|}
\hline Titles & Major contents & Measurement & Period \\
\hline $\begin{array}{l}\text { Preliminary education } \\
\text { and PHP index } \\
\text { measurement }\end{array}$ & $\begin{array}{l}\text { 1. Lesson on how to stain teeth } \\
\text { - Lesson on how to apply a } \\
\text { plaque disclosing agent } \\
\text { - Lesson on how to brush teeth } \\
\text { (rotation method, Watanabe } \\
\text { method) } \\
\text { 2. Lesson on how to use auxiliary } \\
\text { oral hygiene products } \\
\text { (toothbrush, interdental brush, } \\
\text { dental floss) } \\
\text { 3. Lesson on how to use an oral } \\
\text { camera and smartphone } \\
\text { applications } \\
\text { 4. Preliminary PHP index } \\
\text { measurement }\end{array}$ & $\begin{array}{l}\text { 1:1 lesson } \\
\text { (Participant: } \\
\text { Manager) }\end{array}$ & Three sessions \\
\hline $\begin{array}{l}\text { Dental surface } \\
\text { selection and tooth } \\
\text { disclosure }\end{array}$ & $\begin{array}{l}\text { 1. Selecting dental surfaces to be } \\
\text { stained } \\
\text { 2. Applying a plaque disclosing } \\
\text { agent }\end{array}$ & Participant & \multirow{5}{*}{$\begin{array}{c}\text { Run an ICT-based } \\
\text { program } \\
\text {-Ones a day for } 2 \\
\text { weeks } \\
\text { (Monday to Friday) }\end{array}$} \\
\hline Oral camera imaging & $\begin{array}{l}\text { 1. Staining the dental surfaces } \\
\text { with a plaque disclosing agent } \\
\text { 2. Taking images of the stained } \\
\text { teeth } \\
\text { 3. Saving the images }\end{array}$ & Participant & \\
\hline $\begin{array}{l}\text { Upload on the } \\
\text { internet website }\end{array}$ & $\begin{array}{l}\text { 1. Uploading the images of the } \\
\text { stained teeth } \\
\text { 2. Uploading the image files on } \\
\text { the mobile application }\end{array}$ & Participant & \\
\hline $\begin{array}{c}\text { Oral health } \\
\text { management } \\
\text { education } \\
\text { (Remote education) }\end{array}$ & $\begin{array}{l}\text { 1. Checking the uploaded files } \\
\text { and measuring the PHP index } \\
\text { 2. Patient consultation, depending } \\
\text { on the measurement results } \\
\text { 3. Re-education on oral hygiene } \\
\text { management through patient } \\
\text { consultation }\end{array}$ & $\begin{array}{l}\text { Remote education } \\
\text { (Participant } \\
\text {-Manager) }\end{array}$ & \\
\hline Final evaluation & $\begin{array}{l}\text { 1. Measuring the final PHP index } \\
\text { after the end of the program } \\
\text { 2. Statistical analysis }\end{array}$ & $\begin{array}{l}\text { Final program } \\
\text { evaluation }\end{array}$ & \\
\hline
\end{tabular}

\section{Results}

\subsection{General characteristics}

Participants included 11 women (55\%) and 9 men (45\%). Of these, $35 \%$ were in their 20 's, $40 \%$ in their 30 's, and $25 \%$ in their 40 's. The subjective oral health status was good, normal, and poor for $30 \%, 45 \%$, and $25 \%$ of all participants, respectively [Table 3].

Table 3. General characteristics

\begin{tabular}{|c|c|c|c|}
\hline \multicolumn{2}{|c|}{ Variables } & N & $\%$ \\
\hline \multirow{2}{*}{ Sex } & Male & 9 & 45 \\
& Female & 11 & 55 \\
\hline
\end{tabular}




\begin{tabular}{|c|c|c|c|}
\hline \multirow{2}{*}{ Age } & 20 's & 7 & 35 \\
& 30 's & 8 & 40 \\
& 40 's & 5 & 25 \\
\hline \multirow{3}{*}{ Subjective oral health status } & Good & 6 & 30 \\
& Normal & 9 & 45 \\
& Poor & 5 & 25 \\
\hline
\end{tabular}

\subsection{Changes in PHP index between before and after program implementation}

The mean PHP index, which was 2.75 points prior to program implementation, had decreased to 0.95 points after completing the 10 program sessions [Table 4 ].

Table 4. PHP index before and after the program implementation

\begin{tabular}{|c|c|c|c|c|}
\hline Variable & Before & After & Reduction & p-value \\
\hline PHP index & $2.75 \pm 0.23$ & $0.95 \pm 0.21$ & $1.80 \pm 0.23$ & $<0.001 * * *$ \\
\hline
\end{tabular}

\subsection{Changes in PHP index over the course of the program}

The PHP index was measured at 2.75 points at the beginning of the program, but gradually decreased to 2.13 points by the 3 rd session, 1.82 points by the 6 th session, 0.97 points by the 8 th session and 0.95 points by the 10 th session [Table 5].

Table 5. Changes in PHP index over the course of the program

\begin{tabular}{|c|c|c|c|c|c|}
\hline Variable & Session 0 & Session 3 & Session 6 & Session 8 & Session 10 \\
\hline PHP index $\dagger$ & $2.75 \pm 0.23$ & $2.13 \pm 0.20$ & $1.82 \pm 0.23$ & $0.97 \pm 0.19$ & $0.95 \pm 0.21$ \\
\hline
\end{tabular}

\section{Conclusion}

An oral hygiene management program that overcomes time and spatial limitations by providing comprehensive education on oral hygiene care, without requiring patients to visit a hospital, is urgently needed in the busy modern society, and by patients with chronic diseases who have limited mobility. Considering the increased incidence of oral diseases and continuous increase in dental costs, and the escalating implementation of U-healthcare, we here investigated the effect of a remote oral hygiene management program for reducing dental plaque, based on communication between a hospital and patients. The plaque index of the participants in this study decreased markedly by the end of the program, indicating that the program improved the oral hygiene status of participants by improving their oral hygiene skills, subsequently leading to effective removal of dental plaque. This study illustrates a new oral hygiene management model that may suit the changing dental field by verifying the effectiveness of an oral hygiene program using oral camera.

\section{References}

[1] D. Haluza, D. Jungwirth, "ICT and the future of healthcare: Aspects of pervasive health monitoring," Informatics for Health and Social Care, vol.43, pp.1-11, (2018) DOI: 10.1080/17538157.2016.1255215 
[2] H. Payne, C. Lister, J. West, and J. Bernhardt, "Behavioral functionality of mobile apps in health interventions: A systematic review of the literature," JMIR mHealth uHealth, vol.3, no.1, pp.1-9, (2015) DOI: 10.2196/mhealth.3335

[3] F. McKay, C. Cheng, and C. Cheng, "Evaluating mobile phone applications for health behaviour change: A systematic review," J. Telemed. Telecare, vol.24, pp.22-30, (2018)

[4] "Exploring attitudes of healthcare professionals towards ICT-based interventions for nursing home residents with dementia: a mixed-methods approach," Contemporary Nurse, vol. 54, pp.13-25, (2018)

[5] S. S. Baek, "A study on the changes of obese employees' BMI, psychological wellbeing index based on wellness program by ICT," M.S. thesis, Yonsei University, Seoul, (2015)

[6] A. G. Logan AG, W. J. McIsaac, A. Tisler, M. J. Irvine, A. Saunders, A. Dunai, C. A. Rizo, D. S. Feig, M. Hamill, M. Trudel, and J. A. Cafazzo, "Mobile phone-based remote patient monitoring system for management of hypertension in diabetic patients," Am. J. Hypertension, vol.20, no.9, pp.942-948, (2007)

[7] J. I. Hong Joo, "The improvement plans of legal framework and regulations of IoT healthcare service," Kangwon Law Review, vol.50, pp.801-837, (2017)

[8] M. J. Cho, "Effective management interval focused on professional mechanical tooth cleaning," J. Dent. Hyg. Sci, vol.17, no.6, pp.508-515, (2017)

[9] A. Sheiham, "Public health aspects of periodontal diseases in Europe," J. Clin. Periodontol, vol.18, no.6, pp.362-369, (1991)

[10] P. Axelsson, B. Nyström, and J. Lindhe, "The long-term effect of a plaque control program on tooth mortality, caries and periodontal disease in adult," J. Clin. Periodontol, vol.31, pp.749-757, (2004)

\section{Authors}

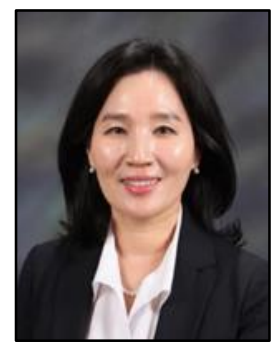

\section{Sun-ju Kim}

Received the M.S. degree in public health from Chung-ang University, Seoul, Korea, in 2003 and the Ph.D. degree in public health from Seoul University, Seoul, Korea in 2010. From 2003 to 2009, she was an assistant professor at department of dental hygiene in Byuksung College, Gimje, Korea. Since 2010, she has been working as an associate professor at Department of Dental hygiene, College of Health and Sciences in Cheongju University, Cheongju, Korea. Her research interest includes the dental hygiene education, community oral health and preventive dental hygiene. 